\section{PSQ-051 IMMUNE RELATED ADVERSE EVENTS IN CANCER PATIENTS TREATED WITH CONTROL POINT INHIBITORS}

A Santiuste Roman*, M Bello Crespo, I Segui Gregori, M Montero Hernandez, S Gea Navarrete, E Soler Company. Hospital Pharmacist, Hospital Arnau De Vilanova, Valencia, Spain

\subsection{6/ejhpharm-2020-eahpconf.368}

Background and importance Despite the clinical benefits of therapy with control point inhibitors in several malignancies, this inhibition is closely linked to a series of immune related adverse events (irAEs). The early detection and management of these is of vital importance.

Aim and objectives To identify and describe irAEs with programmed cell death protein 1 (PD-1) inhibitors and programmed death ligand 1 (PD-L1) inhibitors in clinical practice.

Material and methods A retrospective, descriptive, observational study was conducted in a 400 bed hospital in patients treated with immunotherapy (IT) from 1 January 2016 to 30 October 2018. Variables were age, gender, type of tumour, stage, IT, irAEs and grade, cycles until irAE appearance, irAE treatment and IT suspension. The electronic medical history was reviewed in OrionClinic and IT treatment in Farmis-Oncofarm. The causality of irAEs was ascertained on the basis of the European Society for Medical Oncology (ESMO) algorithms. Statistical analysis was performed with SPSS V.15.

Results A total of 127 patients were treated with an average age of 65 years (range 36-88) and 75\% were women: 76\% of patients had non-microcytic lung cancer, $7 \%$ head-neck, $6 \%$ bladder, $5 \%$ breast, $4 \%$ renal, $2 \%$ melanoma and colorectal cancer. In $67 \%$ of patients, stage IV tumours were found, in $27 \%$ stage III, in $4 \%$ stage II and in $2 \%$ stage I. Nivolumab was prescribed in $54 \%$ of patients, pembrolizumab in $26 \%$, atezolizumab in $13 \%$ and durvalumab in $7 \%$. Fifty-two irAEs were identified. The average number of cycles until irAE appearance was 3.25 (range 1-57). The main irAEs were cutaneous (37\%), gastrointestinal (23\%), pneumonitis (14\%) and endocrinological (8\%); 64\% grade I, $25 \%$ grade II, $12 \%$ grade III and no grade IV. Treatment was given for $66 \%$ of irAEs: oral corticoids (52\%), topical corticoids (17\%), antihistamines (12\%) and hormone replacement therapy $(5 \%)$. IT was resumed in $83 \%$ of patients. By the end of the study period, $31 \%$ of patients remained on therapy. Non-continuity was due to progression (55\%), irAEs (10\%) and other reasons (4\%).

Conclusion and relevance The most frequent irAEs in patients receiving IT were cutaneous and gastrointestinal, mostly transitory and grades I-II. They were mostly resolved with corticotherapy and antihistamines. Management of irAEs was presented on the basis of clinical experience; cooperation of patients, caregivers and healthcare professionals is required to watch over their safety to obtain the maximum efficacy with the lowest irAEs possible.

\section{REFERENCES AND/OR ACKNOWLEDGEMENTS}

No conflict of interest.

\section{PSQ-052 EARLY RESULTS FROM THE EFFECTIVENESS AND SAFETY EVALUATION OF BIOSIMILAR RITUXIMAB AND BRAND RITUXIMAB IN GLOMERULAR INFLAMMATORY DISEASE}

${ }^{1} \mathrm{C}$ Varon-Galcera*, ${ }^{2} \mathrm{RP}$ Bury-Macias, ${ }^{1} \mathrm{M}$ Larrosa-Garcia, ${ }^{3} \mathrm{M}$ Martinez-Gallo, ${ }^{3} \mathrm{~K}$ MendozaParedes, ${ }^{2}$ Agraz-Pamplona, ${ }^{3} \mathrm{M}$ Hernandez-Gonzalez, 'MQ Gorgas-Torner, 'B MontoroRonsano. 'Vall Hebron Barcelona Hospital Campus, Department of Hospital Pharmacy, Barcelona, Spain; ${ }^{2}$ Vall Hebron Barcelona Hospital Campus, Department of Nephrology, Barcelona, Spain; ' ${ }^{3}$ all Hebron Barcelona Hospital Campus, Department of Immunology, Barcelona, Spain

\subsection{6/ejhpharm-2020-eahpconf.369}

Background and importance Biosimilar drugs should have proven clinical efficacy comparable with the referring brand to obtain authorisation from medicine regulatory agencies. Nevertheless, the effectiveness and safety of off-label uses are not always proved.

Aim and objectives The endpoint of this study was to evaluate the early effectiveness and safety of biosimilar rituximab compared with the referring brand for an off-label use: glomerular inflammatory renal disease.

Material and methods This was an observational retrospective study in patients with glomerular inflammatory disease treated with rituximab (1 $\mathrm{g}$ single dose or $1 \mathrm{~g}$ two doses). Patients receiving rituximab for the first time between March 2018 and March 2019 were included. Information on patient demographics, underlying disease and associated treatment was collected from the patient medical records. Laboratory data including creatinine, proteinuria, leucocyte and lymphocyte count were collected before (0-60 previous days) and after (0-60 days after) administration of rituximab.

Results Six patients (mean age 59 years (26-74); 50\% women) with baseline $6.52 \pm 2.00 \times 10^{9} / \mathrm{L}$ leucocyte count, 2.28 $\pm 1.10 \times 10^{9} / \mathrm{L}$ lymphocyte count, $1.63 \pm 1.04 \mathrm{mg} / \mathrm{dL}$ creatinine and $6.84 \pm 3.36 \mathrm{~g} / 24$ hours proteinuria were treated with biosimilar rituximab. Thirteen patients (mean age 58 years (25$81) ; 30 \%$ women) with baseline $9.80 \pm 4.62 \times 10^{9} / \mathrm{L}$ leucocyte count, $1.92 \pm 1.13 \times 10^{9} / \mathrm{L}$ lymphocyte count, $1.61 \pm 0.85 \mathrm{mg} / \mathrm{dL}$ creatinine and $5.81 \pm 4.55 \mathrm{~g} / 24$ hours proteinuria were treated with brand rituximab. After rituximab administration, these values were $6.13 \pm 1.94 \times 10^{9} / \mathrm{L}$ leucocyte count, 1.30 $\pm 0.59 \times 10^{9} / \mathrm{L}$ lymphocyte count, $1.16 \pm 1.19 \mathrm{mg} / \mathrm{dL}$ creatinine, $3.29 \pm 0.58 \mathrm{~g} / 24$ hours and proteinuria for the biosimilar group, and $8.77 \pm 3.78 \times 10^{9} / \mathrm{L}$ leucocyte count, 1.67 $\pm 1.13 \times 10^{9} / \mathrm{L}$ lymphocyte count, $1.56 \pm 1.19 \mathrm{mg} / \mathrm{dL}$ creatinine and $3.36 \pm 2.20 \mathrm{~g} / 24$ hours proteinuria for the brand group. After rituximab administration, CD19+ lymphocytes become negative in both groups (5/5 for the biosimilar group; $6 / 6$ for the brand group). There were two total remissions, one partial remission and three non-responses with the biosimilar rituximab, and one total remission, five partial remissions and seven non-responses with the brand rituximab. Biosimilar rituximab was well tolerated in 6/6 patients and no infections developed. Brand rituximab was well tolerated in $11 / 13$ patients and $4 / 13$ patients showed an infectious episode. No significant differences were observed for the treatment response between the two groups. 